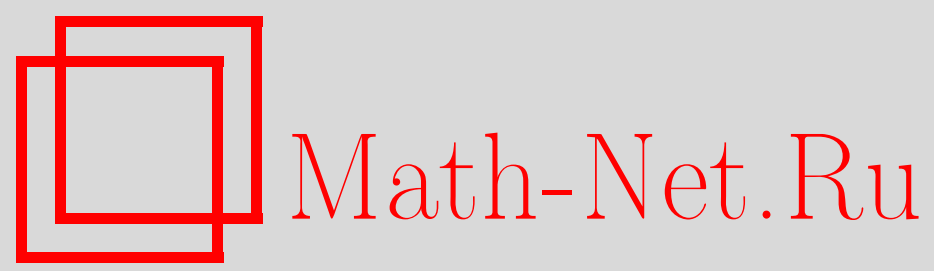

А. П. Семин, А. М. Глезер, В. Е. Громов, С. В. Коновалов, Влияние микролегирования на механические свойства аморфных сплавов, Вестн. Сам. гос. техн. ун-та. Сер. Физ.-мат. науки, 2004, выпуск 27, 172-175

DOI: https://doi.org/10.14498/vsgtu298

Использование Общероссийского математического портала Math-Net.Ru подразумевает, что вы прочитали и согласны с пользовательским соглашением

http: //www.mathnet.ru/rus/agreement

Параметры загрузки:

IP: 3.85 .73 .92

26 апреля 2023 г., $11: 25: 10$ 
Здесь $q$ - масса метаемого элемента $\left(\mathrm{C}_{\mathrm{q}}=1 \Gamma / \mathrm{cm}^{3}\right.$ для первой строки данных $) ; P_{0}$ - давление на дно канала; $P_{1}$ - давление на поршень слева; $P_{2}$ - давление на поршень справа; $P_{\text {эл }}$ давление на элемент; $I_{\mathrm{kI}}, I_{\mathrm{kII}}$ - импульсы составов в I и II областях; $T_{3}$ - время задержки зажигания; $F$ - сила состава.

В табл. 2 приведены результаты расчёта системы с относительно коротким каналом $\left(\mathrm{C}_{\mathrm{q}}=3 \Gamma / \mathrm{cm}^{3}\right)$.

Т а б л и ц а 2

Параметры системы с относительно тяжёлым элементом

\begin{tabular}{|c|c|c|c|c|c|c|c|c|c|}
\hline $\begin{array}{l}\mathrm{q}, \\
\Gamma\end{array}$ & $\begin{array}{l}\mathrm{V}, \\
\mathrm{M} / \mathrm{c}\end{array}$ & $\begin{array}{l}\mathrm{P}_{0}, \\
\text { МПа }\end{array}$ & $\begin{array}{l}\mathrm{P}_{1}, \\
\text { МПа }\end{array}$ & $\begin{array}{l}\mathrm{P}_{2}, \\
\text { МПа }\end{array}$ & $\begin{array}{l}\mathrm{P}_{\text {эл }} \\
\mathrm{MПа}\end{array}$ & $\mathrm{I}_{\mathrm{kl}}, \mathrm{M}$ Па ${ }^{\mathrm{c}} \mathrm{c}$ & $\mathrm{I}_{\mathrm{kII}}, \mathrm{MПa}{ }^{*} \mathrm{c}$ & $\begin{array}{l}\mathrm{T}_{3}, \\
\mathrm{Mc}\end{array}$ & $\begin{array}{l}\mathrm{F}, \\
\mathrm{\kappa} \Gamma^{*} \text { дм/кГ }\end{array}$ \\
\hline 71 & 2455 & 458 & 402 & 833 & 1033 & 0,407 & 0,146 & 2,107 & $1,02 * 10^{6}$ \\
\hline
\end{tabular}

По сравнению с классической схемой метания выигрыш в начальной скорости по данным табл. 2 составляет $29 \%$, что говорит о перспективности использования присоединенного заряда для обеспечения повышенных скоростей метания элементов. Проведенные ранее исследования показали, что использование присоединенного заряда обеспечивает достижение повышенных скоростей метания без увеличения максимального давления в каморе метательной системы по сравнению с классической схемой.

Таким образом, в работе обоснована перспективность использования схемы метания с присоединённым зарядом для проведения экспериментальных исследований.

БИБЛИОГРАФИЧЕСКИЙ СПИСОК:

1. И.Г.Русяк, В.М.Ушаков. Внутрикамерные гетерогенные процессы в ствольных системах. Екатеринбург: УрО PAH, 2001, $259 \mathrm{c}$.

2. В.Н.Вилюнов.Теория зажигания конденсированных веществ. Новосибирск:Наука, Сиб. отд-ние, 1984. 189c.

3. А.И.Сафронов. Патент 9061. Патрон многосекционный. 95115246/20. 16.01.99. Бюлл. №1. МКИ F42B7/00.

УДК 669.018.569.12.765

А.П. Семин, А.М. Глезер, В.Е. Громов, С.В. Коновалов

\section{ВЛИЯНИЕ МИКРОЛЕГИРОВАНИЯ НА МЕХАНИЧЕСКИЕ СВОЙСТВА АМОРФНЫХ СПЛАВОВ}

Исследовано положительное влияние микролегирования небольших добавок (0,5-2,0 ат.\%) алюминия и меди на механические свойства и технологичность сплавов системы Fe-Ni-Cr-P-Si-B. Meтодом оже-спектроскопии показано, что влияние алюминия связано с поверхностно-активным поведением: обогащением (на порядок и более) поверхностных слоев алюминием и соответствующим перераспределением в этих слоях основных металлических компонентов сплава.

Аморфные сплавы, полученные для ряда металлических систем, обладают механическими свойствами, существенно превосходящими свойства кристаллических материалов. Характерной отличительной чертой для аморфных сплавов является высокая прочность, близкая к теоретически возможному пределу, а также достаточно высокие пластичность и вязкость разрушения [1]. В настоящее время одним из наиболее эффективных методов получения аморфных сплавов в виде ленты толщиной 30-40 мкм с высокими механическими свойствами является закалка из жидкого состояния [2]. Метод заключается в осуществлении резкой закалки расплава со скоростью $\approx 10^{6}$ град/сек.

Данная работа ставила своей целью исследование влияния микролегирования алюминием и медью на механические свойства аморфных сплавов системы Fe-Ni-Cr-P-Si-B с уровнем прочности свыше 2000 МПа и достаточным сцеплением с пластмассой при изготовлении композитов типа металл-пластмасса. Металлический компонент такого композита должен сочетать высокую прочность, достаточную пластичность, хорошую адгезионную прочность, определенную коррозионную стойкость и содержать минимальное количество дефицитных и дорогостоящих компонентов.

Анализ литературных данных показал, что повышенную прочность, температурную стабильность и пластичность в исходном (быстрозакаленном) состоянии проявляют аморфные 172 
сплавы на основе железа, в которых содержится до 40 ат.\% $\mathrm{Cr}$ и Ni, до 35 ат.\% В, до 8 ат.\% Мо, а также в различных сочетаниях C, P, и $\mathrm{Si}$ [3]. Кроме того, рекомендовано дополнительное легирование аморфных сплавов, используемых в качестве конструкционных материалов, тугоплавкими металлами, алюминием и медью [4].

С целью экономии использования в разрабатываемом аморфном сплаве дефицитных и дорогостоящих материалов, таких, как никель и бор, был проведен первоначальный поиск на базе системы Fe-Cr-P-B путем последовательной замены бора на фосфор в хорошо известном из литературы аморфном сплаве $\mathrm{Fe}_{70} \mathrm{Cr}_{15} \mathrm{~B}_{15}$. В табл.1 приведены результаты измерения механических свойств аморфных сплавов системы Fe-Cr-P-B, выплавленных из одних и тех же шихтовых материалов и в идентичных технологических условиях. Полученные ленточные образцы имела ширину 5 мм для всех трех изученных сплавов. Следует отметить, что даже для сплава $\mathrm{Fe}_{70} \mathrm{Cr}_{15} \mathrm{~B}_{10} \mathrm{P}_{5}$, где степень замещения бора на фосфор невелика, обнаруживается малая прочность и пластичность, хотя уровень сопротивления тепловым охрупчивающим воздействиям (температура отпускной хрупкости $T_{x}$ ) и значения твердости достаточно высоки. Сплав $\mathrm{Fe}_{70} \mathrm{Cr}_{15} \mathrm{~B}_{5} \mathrm{P}_{10}$, также обладая невысокой прочностью, проявляет кроме того существенно более низкую сопротивляемость охрупчивающим термическим воздействиям. К сожалению, сплав $\mathrm{Fe}_{70} \mathrm{Cr}_{15} \mathrm{P}_{15}$ не удалось получить пластичным в исходном состоянии во всем использованном в работе интервале варьирования технологических параметров.

Известно, что введение никеля положительно влияет на пластичность аморфных сплавов на основе Fe-P и Fe-Si-P-B вследствие разрушения образуемых в расплаве и закаливаемых при получении ленты комплексов типа $\mathrm{Fe}_{3} \mathrm{~B}$ [5]. Это позволяет рассматривать следующим этапом частичное замещение железа никелем, а также введение кремния в систему Fe-Cr-B-P.

Из результатов, представленных в табл.2, видно, что само по себе введение $\mathrm{Ni}$ и $\mathrm{Si}$ не приводит к улучшению механических свойств. Только сплав $\mathrm{Fe}_{60} \mathrm{Ni}_{10} \mathrm{Cr}_{10} \mathrm{P}_{14} \mathrm{Si}_{4} \mathrm{~B}_{2}$ оказался технологичным и обладал средним уровнем прочности, твердости и сопротивления охрупчивающим термическим воздействиям.

Т а б л и ц а 1

Химический состав и механические свойства сплавов Fe-Cr-B-P

\begin{tabular}{|c|c|c|c|c|c|}
\hline № & Состав & $d$, мкм & $T_{x},{ }^{0} \mathrm{C}$ & $H V$, МПа & $\sigma_{b}$, МПа \\
\hline 1 & $\mathrm{Fe}_{70} \mathrm{Cr}_{15} \mathrm{~B}_{10} \mathrm{P}_{5}$ & $18-21$ & 220 & 10300 & 1060 \\
\hline 2 & $\mathrm{Fe}_{70} \mathrm{Cr}_{15} \mathrm{~B}_{5} \mathrm{P}_{10}$ & $21-25$ & 160 & 9000 & 1060 \\
\hline 3 & $\mathrm{Fe}_{70} \mathrm{Cr}_{15} \mathrm{P}_{15}$ & $18-20$ & исх.хр. & 8400 & 770 \\
\hline
\end{tabular}

Примечание: $d$ - толщина ленты, $\sigma_{b}-$ предел прочности, $T_{x}-$ температура отпускной хрупкости, HV - микротвердость.

Т а б л и ц а 2

Химический состав и механические свойства сплавов Fe-Ni-Cr-P-Si-B

\begin{tabular}{|c|c|c|c|c|c|}
\hline № & Состав & $d$, мкм & $T_{x},{ }^{0} \mathrm{C}$ & $H V$, МПа & $\sigma_{6}$, MПа \\
\hline 1 & $\mathrm{Fe}_{75} \mathrm{Ni}_{5} \mathrm{Cr}_{10} \mathrm{P}_{15}$ & $18-20$ & Исх.хр. & 8150 & 1020 \\
\hline 2 & $\mathrm{Fe}_{69} \mathrm{Ni}_{10} \mathrm{Cr}_{6} \mathrm{P}_{12} \mathrm{~B}_{3}$ & $17-18$ & Исх.xp. & 7400 & 970 \\
\hline 3 & $\mathrm{Fe}_{68} \mathrm{Ni}_{10} \mathrm{Cr}_{6} \mathrm{P}_{12} \mathrm{Si}_{3} \mathrm{~B}_{1}$ & $11-13$ & Исх.xp. & 7200 & 900 \\
\hline 4 & $\mathrm{Fe}_{50} \mathrm{Ni}_{10} \mathrm{Cr}_{10} \mathrm{P}_{14} \mathrm{Si}_{14} \mathrm{~B}_{2}$ & $19-20$ & Исх.xp. & 9300 & 1240 \\
\hline
\end{tabular}

Исследование влияния микродобавок $\mathrm{Al}$ и $\mathrm{Cu}(0,5-2,0$ ат.\%) на механические свойства вышеописанных аморфных сплавов, позволило выделить влияние $\mathrm{Al}$ и $\mathrm{Cu}$ в системах с полным набором металлоидов и в системе только с одним металлоидом (фосфором). Оба сплава в исходном состоянии были нетехнологичны и проявляли в различной степени склонность к хрупкому разрушению. Анализ результатов, представленных в табл.3, показывает, что введение алюминия в состав сплавов приводит к качественному изменению механических свойств сплавов обеих систем. Особенно ярко этот эффект проявляется в системе Fe-Ni-Cr-P, где введение Al позволяет получить пластичную высокопрочную ленту с высоким качеством поверхности. Введение в эту систему 0,5 ат.\% Сu приводило к резкому снижению толщины ленты (при идентичных параметрах получения) и к некоторому снижению прочности образца. Возможно, это связано с появлением сквозных дефектов («проколов») в ленточных образцах малой толщины. Следует отметить, что введение Al в систему Fe-Ni-Cr-P-Si также приводит к повышению технологичности сплава, к получению ленты с высоким качеством поверхности и к росту прочно- 
сти. Введение же 0,5 ат.\% $\mathrm{Cu}$ дополнительно к $\mathrm{Al}$ приводит к росту значений $T_{x}$ и пластичности, а также к некоторому снижению прочности.

Химический состав и механические свойства сплавов Fe-Ni-Cr-P-Si-B-Al-Cu

\begin{tabular}{|c|c|c|c|c|c|}
\hline № & Состав & $d$, мкм & $T_{x},{ }^{0} \mathrm{C}$ & $H V$, MПа & $\sigma_{6}$, МПа \\
\hline 1 & $\mathrm{Fe}_{70} \mathrm{Ni}_{5} \mathrm{Cr}_{10} \mathrm{P}_{15}$ & $18-20$ & Исх.хр. & 8150 & 1400 \\
\hline 2 & $\mathrm{Fe}_{69} \mathrm{Ni}_{5} \mathrm{Cr}_{10} \mathrm{P}_{15} \mathrm{Al}_{1}$ & $21-24$ & 210 & 9000 & 1700 \\
\hline 3 & $\mathrm{Fe}_{68,5} \mathrm{Ni}_{5} \mathrm{Cr}_{10} \mathrm{P}_{15} \mathrm{Al}_{1} \mathrm{Cu}_{0,5}$ & $12-14$ & 210 & 8150 & 1340 \\
\hline 4 & $\mathrm{Fe}_{60} \mathrm{Ni}_{10} \mathrm{Cr}_{10} \mathrm{P}_{14} \mathrm{Si}_{4} \mathrm{~B}_{2}$ & $19-22$ & Иcх.xp. & 9300 & 1240 \\
\hline 5 & $\mathrm{Fe}_{58} \mathrm{Ni}_{10} \mathrm{Cr}_{10} \mathrm{P}_{14} \mathrm{Si}_{4} \mathrm{~B}_{2} \mathrm{Al}_{2}$ & $18-20$ & 170 & 9000 & 1660 \\
\hline 6 & $\mathrm{Fe}_{58,5} \mathrm{Ni}_{10} \mathrm{Cr}_{10} \mathrm{P}_{14} \mathrm{Si}_{4} \mathrm{~B}_{2} \mathrm{Al}_{1} \mathrm{Cu}_{0,5}$ & $16-19$ & 190 & 9000 & 1360 \\
\hline 7 & $\mathrm{Fe}_{57,5} \mathrm{Ni}_{10} \mathrm{Cr}_{10} \mathrm{P}_{14} \mathrm{Si}_{4} \mathrm{~B}_{2} \mathrm{Al}_{2} \mathrm{Cu}_{0,5}$ & $19-21$ & 190 & 9000 & 1480 \\
\hline
\end{tabular}

Для выявления причин столь существенного положительного влияния $\mathrm{Al}$ на механические свойства аморфных сплавов был проведен послойный анализ химического состава методом оже-спектроскопии с применением методики ионного травления на приборе LHS-10 SAM. Количественный анализ проводился в предположении, что амплитуда оже-пика данного элемента пропорциональна количеству атомов этого элемента, находящемуся под электронным зондом. Для наглядности результаты послойного анализа представлены в виде отношения $c_{i} / c_{F e}$, где $c_{F e}$ - атомное содержание $\mathrm{Fe}$ на заданной глубине и $c_{i}$ - атомное содержание $i$-го элемента на той же глубине. Ошибка количественного анализа при использовании эталонов составляла $\pm 10 \%[6]$.

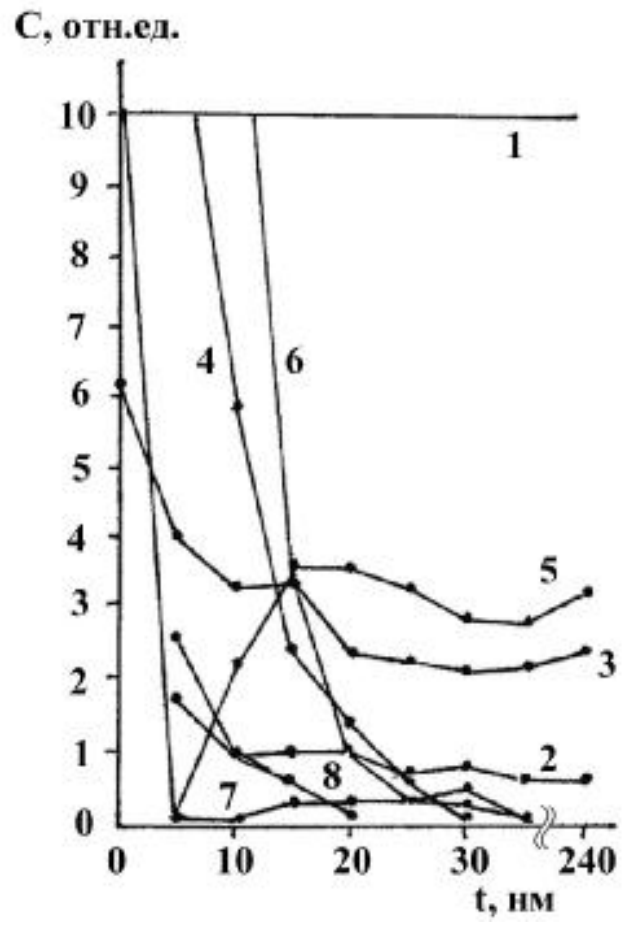

$a$

\section{С, отн.ед.}

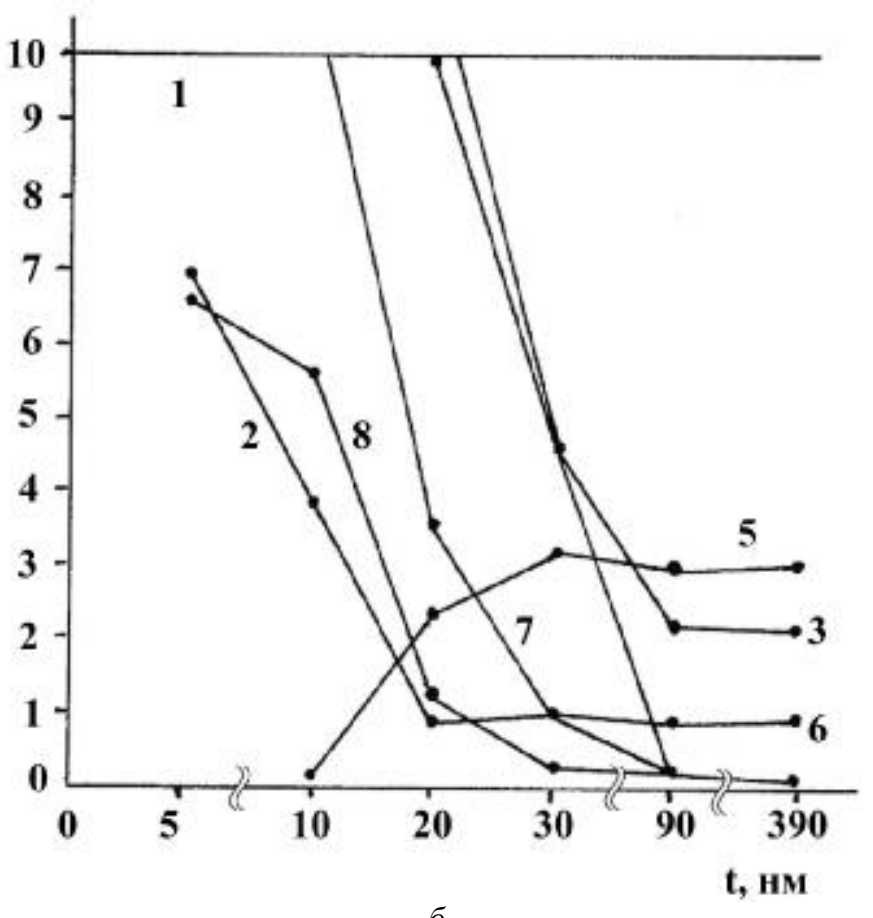

$\sigma$

Распределение элементов на свободной поверхности аморфных сплавов $\mathrm{Fe}_{69} \mathrm{Ni}_{5} \mathrm{Cr}_{10} \mathrm{P}_{15} \mathrm{Al}_{1}(\mathrm{a}), \mathrm{Fe} \mathrm{Ni}$ $\mathrm{Cr} \mathrm{P} \mathrm{Al} \mathrm{Cu} \mathrm{(б):} 1$ - железо, 2 - никель, 3 - хром, 4 - алюминий, 5 - фосфор, 6 - кислород, 7 - углерод, 8 - сера.

Анализ оже-спектров (см. рис.) показал, что Al ведет себя как поверхностно-активный элемент, образуя на свободной поверхности ленточных образцов соединения с кислородом на глубину до 20 нм, где содержание Al в несколько раз превышает содержание Fе. Следует отметить, что распределение $\mathrm{Cr}$ в приповерхностном слое свободной поверхности сплавов, легированных Al, также существенно отличается. Так, например, в сплаве $\mathrm{Fe}_{65} \mathrm{Ni}_{15} \mathrm{Cr}_{10} \mathrm{P}_{15}$ в приповерхностном слое преобладают атомы хрома, лишь на глубине $\approx 80$ нм сравниваясь по количественному соотношению с атомами железа. Введение в этот сплав 1 ат.\% Al наряду с отмечен- 
ным выше качественным изменением уровня механических свойств приводит и к качественному изменению характера распределения элементов в приповерхностном слое. Слабые признаки наличия атомов хрома отмечаются лишь на глубине, соответствующей 10 нм, и содержание атомов хрома остается на очень низком уровне до максимальной исследованной глубины травления, соответствующей 400 нм. С другой стороны, для сплава без $\mathrm{Al}$ характерно практически постоянное содержание атомов никеля в слое от поверхности до 1500 нм. Для сплава с 1 ат.\% $\mathrm{Al}$ отмечена узкая зона (от 10 до 20 нм) небольшого обогащения атомами никеля. Для сплава, легированного 1 ат.\% $\mathrm{Al}$ и 0,5 ат.\% $\mathrm{Cu}$, характерна, в общем, та же картина распределения элементов, но в несколько сглаженном виде.

Сформулируем основные выводы.

Выполнено исследование двух композиций сплавов Fe-Ni-Cr-P-Si-B, состав которых соответствует высокому уровню механических свойств (предел прочности - $2000 \mathrm{MПа,} \mathrm{температу-}$ ра отпускной хрупкости $\left.-210-240^{\circ} \mathrm{C}\right)$. Выявлено существенное влияние небольших добавок $(0,5-2,0$ ат.\%) алюминия и меди на технологичность и механические свойства изученных сплавов. Методом оже-спектроскопии показано, что влияние алюминия связано с поверхностноактивным поведением: обогащением (на порядок и более) поверхностных слоев алюминием и соответствующим перераспределением в этих слоях основных металлических компонентов сплава.

\section{БИБЛИОГРАФИЧЕСКИЙ СПИСОК}

1. Глезер А.М., Молотилов Б.В. Структура и механические свойства аморфных сплавов. М.: Металлургия, 1992. $208 \mathrm{c}$.

2. Люборский Ф.Е. Аморфные металлические сплавы. М.: Металлургия, 1987. 583 с.

3. Глезер А.М., Молотилов Б.В., Утевская О.Л. Механические свойства аморфных сплавов // Металлофизика. 1983. T.5. №1. C. 29-45.

4. Глезер А.М., Утевская О.Л. Особенности измерения механических свойств тонких ленточных материалов // Композиционные прецизионные материалы. М.: Металлургия, 1983. С.78-82.

5. Семин А.П., Глезер А.М., Громов В.Е. Влияние технологических параметров, химического состава и режимов термической обработки на механические свойства аморфных сплавов Fe-Ni-P // Известия ВУЗов. Черная металлургия. 2003. №12. С.58-61.

6. Налимов В.В. Теория эксперимента. М.: Наука, 1971. 207 с.

УДК 621.793 .18

\section{Н.А. Смоланов, Н.А. Панькин}

\section{ВЛИЯНИЕ ИОННО-ПЛАЗМЕННОЙ ОБРАБОТКИ НА МЕХАНИЧЕСКИЕ СВОЙСТВА ИЗДЕЛИЙ ДЛЯ ПРОИЗВОДСТВА КАБЕЛЯ}

Проведено исследование влияния режимов ионно-плазменной обработки на механические свойства и атомно-кристаллическую структуру изделий для производства кабеля.

Постановка задачи. Метод вакуумного ионно-плазменного модифицирования поверхности с целью её упрочнения и повышения коррозионной стойкости нашёл достаточно широкое применение в индустриальной промышленности и машиностроении [1]. Качество получаемых покрытий зависит от множества факторов, основным из которых является присутствие макрочастиц материала катода в потоке плазмы вакуумного дугового разряда. Применение плазменного источника с магнитной стабилизацией катодного пятна и магнитной фокусировкой плазменного потока [2] позволяет управлять концентрацией макрочастиц в составе формирующейся поверхности (плёнки).

Учитывая противоречивый характер литературных данных о влиянии капельной фазы на фазовый состав, структуру и свойства образующейся плёнки [2-11], нами были проведены, следуя [3], технологические и лабораторные исследования при разработке и использовании конкретного технологического процесса: создание износостойкого покрытия на деталях для производства электротехнического кабеля. 